\title{
Musculoskeletal effects of heavy backpacks in school children of 11-14 years of age
}

\author{
Mohan A. Patil ${ }^{1}$, Sumana $S^{2}$, Shagale $\mathbf{N}^{3}$ \\ ${ }^{1}$ Dr. Mohan A. Patil, Professor of Pediatrics. ${ }^{2}$ Dr. Sumana S, Senior Post Graduate Student, ${ }^{3}$ Dr. Nithin Shagale, Junior \\ Post Graduate Student. All are attached to D.Y. Patil Medical College Kolhapur, Maharashtra, India.
}

Address for Correspondence: amohanpatil@gmail.com

\begin{abstract}
Background/Objectives: High and increasing prevalence of back pain in children and adolescent is matter of concern. Prevalence varies regionally as it depends on many variables. Heavy backpack is one of the important underlying causes. Adolescent spine is in the critical stage of development in the age group of 11-14 years. This study was carried out to decide regional cutoffs of heavy relative weights of backpacks in male and female children. Methods: In a community based co-relational study 249 male and 251 female children in the age group of 11-14 yrs using backpack from 6 schools of Kolhapur city, Maharashtra, India were studied. Musculoskeletal effects were noted as per Nordic Musculoskeletal Questionnaire. Data was recorded in MS Excel worksheet and statistically analyzed using computer assisted statistical software SPSS Package Version-20. Results: Musculoskeletal problems due to heavy backpacks were found in $60.6 \%$ of children; $55.02 \%$ males and $66.53 \%$ females. Prevalence increased with increasing relative weight of backpack both in male and female children. With relative weight of backpack $\leq 11 \%$, most children were asymptomatic. Relative weight of $12 \%$ to $13 \%$ showed statistically insignificant prevalence of musculoskeletal symptoms. With a relative weight of backpack $\geq 14 \%$ in males and $\geq 15 \%$ in females, prevalence of musculoskeletal symptoms steeply increased. Conclusions: Relative weight of backpack $\leq 11 \%$ is safe to carry. As relative weight of backpack increases to $\geq 15 \%$, majority of adolescent children in the age group of 11-14 years in this region are at risk of developing musculoskeletal adverse effects.
\end{abstract}

Keywords: Backpack, Musculoskeletal effects

\section{Introduction}

Carrying backpacks is common practice in children and is prevalent all over the world including India. Adolescent spine is in critical stage of development. Selection of backpack with unsafe characteristics, wrong method of carrying it and use of heavy backpacks is associated with musculoskeletal, postural and systemic adverse effects. Most studies endorse the observation of overall increasing incidence of backache in children and its correlation with increasing weight of backpacks. Use of heavy backpacks by children especially in this sensitive period of vertebral column growth, may cause possible adverse effect on spine, musculoskeletal system, posture, and respiratory system making them prone for development of mobility problems during adulthood. [1-12].

Manuscript received: $20^{\text {th }}$ April 2016

Reviewed: $7^{\text {th }}$ May 2016

Author Corrected; $18^{\text {th }}$ May 2016

Accepted for Publication: $4^{\text {th }}$ June 2016
However there are wide variations in prevalence of musculoskeletal symptoms related to use of backpacks. Similarly cutoffs for relative weight of backpack i.e. actual weight of backpack as compared to weight of child; to call it safe or unsafe have wide variations. These variations may be due to variations in the constitutional built up, relative weight of backpack, parental awareness and behavioral practices, difference in schooling pattern and curriculum, differences in books, accessories and quality of backpacks. Hence there is need to decide regional age and gender related cutoffs of relative weight of safe backpacks so as to increase awareness of children, parents, teachers and policy makers. It will help in designing strategies to prevent backpack related musculoskeletal injuries.

Studies done all over the world indicate relative weight of backpack $\leq 10 \%$ is mostly safe and relative weight of 
$\geq 15 \%$ is associated with high risk of adverse musculoskeletal effects. However owing to anthropometrical differences in children of different geographical locations, there is need to generate regional data. There are only few studies giving exact cutoffs of relative weight in given population. Such study was not conducted in this region earlier, hence this study was conducted. Adolescent school children using backpacks, in the age group of 11-14 years was selected as it is considered to be a critical age group for spine development. Effects of relative weight of backpacks were compared with musculoskeletal symptoms and signs in relation to age and gender.

\section{Material and Methods}

A community based co-relational study was designed. Study was conducted from August 2014 to July 2015. Children from various schools in the age group of 11 to 14 years in Kolhapur city, Maharashtra state, India carrying backpacks were selected. 14 schools were targeted out of which 6 schools were included after permission from school authorities, parents and Institutional Ethical Committee. Schools were selected to represent different strata of the community. Students studying in class 7th, 8th and 9th with an age group of 11-14 years using school bags were randomly selected. Total of 500 children, including 249 male children and 251 female children participated in the study. The subjects were screened as per the inclusion and exclusion criteria. Inclusion criteria were children in the age group of 11 to 14 years carrying backpacks to school and absence of the musculoskeletal symptoms if any, during school vacation. Exclusion criteria were children with known obvious skeletal deformities of spine, and limbs, children having any known orthopedic, muscular or rheumatoid disease, children having Body Mass Index (BMI) less than or more than the normal range according to standard Indian Academy of Pediatrics (IAP) growth charts for adolescents, children involved in competitive sports and excessive use of computer for more than 4 hours.

Schools were visited on unscheduled day and students were told that it was a part of their routine health check up to avoid apprehension and bias. Children were weighed using a digital scale and height was noted on a portable stadiometer. BMI was calculated and plotted on standard IAP growth charts for adolescents. Backpacks with all the contents were weighed as soon as children arrived to the school. Relative weight of the backpack in relation to body weight was calculated. Children were examined in detail to look for any signs of musculoskeletal discomfort. A standardized Nordic Musculoskeletal Questionnaire was filled based on the responses given by children for musculoskeletal complaints of neck, spine, back and shoulders. Musculoskeletal symptoms asked were neck pain, back pain, shoulder pain. Musculoskeletal signs examined were redness below straps, tenderness in neck, spine, back and limitations of spinal movements.

Data received was recorded in MS Excel worksheet. The statistical analysis was done using computer assisted statistical software SPSS Package Version - 20.

\section{Results}

The demographic result showed that mean age and weight of the participants were $12.94 \pm 1.03$ years and $42.85 \pm 7.54 \mathrm{~kg}$ respectively. The mean absolute weight of the backpack was found to be $6.75 \pm 0.99 \mathrm{~kg}$ and relative weight of backpack $15.95 \pm 2.24 \%$. (Table 2). Mean absolute weight of backpack in male and female children was nearly equal (M $6.83 \pm 1.02 \mathrm{~kg}$, F $6.67 \pm 0.95 \mathrm{~kg}$ ). However relative weight of backpack was higher in female children $(16.37 \pm 2.19 \%)$ than that seen in male children (15.52 $\pm 2.22 \%$ ). (Table 3). $60.6 \%$ of participants had musculoskeletal adverse effects related to backpack use. $55.02 \%$ males and $66.53 \%$ females suffered these side effects. All children with musculoskeletal signs had musculoskeletal symptoms also. (Table 4).

All the participants carrying relative backpack weight of $11 \%$ or less did not show any musculoskeletal adverse effects. As relative weight of backpack increased to 12 and 13\%, participants started showing musculoskeletal symptoms however they were not statistically significant. When relative weight of backpack was $14 \%$ and more, musculoskeletal adverse effects became more frequent with increasing weight which was statistically highly significant. (Table 4). Physical signs were noted in participants carrying backpacks with relative weight of more than $16 \%$. Incidence of physical signs was more in females (11.55\%) as compared with males (6.02\%). (Table 4). Out of all 304 symptomatic children musculoskeletal symptoms in the form of neck pain, back pain and shoulder pain were found in 73 (24\%), 255 $(83.88 \%)$ and $247(81.25 \%)$ children respectively. Musculoskeletal signs like redness below the strips, tenderness and limitation of spinal movement were seen in $25(8.2 \%), 42(13.8 \%)$ and $6(1.97 \%)$ children respectively. (Table 5). 
Table-1: Age and sex wise distribution of $\operatorname{cases}(n=500)$.

\begin{tabular}{|c|c|c|c|c|c|c|}
\hline Age (yrs ) & \multicolumn{2}{|c|}{ Male } & \multicolumn{2}{c|}{ Female } & \multicolumn{2}{c|}{ Total } \\
\hline & Number & \% & Number & \% & Number & \% \\
\hline 11 years & 29 & 11.65 & 30 & 11.95 & 59 & 11.80 \\
\hline 12 years & 57 & 22.89 & 44 & 17.53 & 101 & 20.20 \\
\hline 13 years & 82 & 32.93 & 71 & 28.29 & 153 & 30.60 \\
\hline 14 years & 81 & 32.53 & 106 & 42.23 & 187 & 37.40 \\
\hline Total & 249 & 100.00 & 251 & 100.00 & 500 & 100.00 \\
\hline
\end{tabular}

Table-2: Mean parameters and standard deviation of all cases.

\begin{tabular}{|l|c|c|}
\hline Variable & Mean & Standard deviation (sd) \\
\hline Age (years) & 12.94 & 1.03 \\
\hline Weight (kg) & 42.85 & 7.54 \\
\hline Absolute weight of backpack & 6.75 & 0.99 \\
\hline Relative weight of back pack (\%) & 15.95 & 2.24 \\
\hline
\end{tabular}

Table-3: Mean Absolute and Relative weight of backpack.

\begin{tabular}{|c|c|c|c|c|c|c|c|c|}
\hline Age & \multicolumn{4}{|c|}{ Absolute Weight (Kg) } & \multicolumn{3}{c|}{ Relative weight (\% of body weight) } \\
\hline & No & $\begin{array}{c}\text { Male } \\
\text { Mean } \pm \text { sd }\end{array}$ & No & $\begin{array}{c}\text { Female } \\
\text { Mean } \pm \text { sd }\end{array}$ & No & $\begin{array}{c}\text { Male } \\
\text { Mean } \pm \text { sd }\end{array}$ & $\begin{array}{c}\text { Fomale } \\
\text { Mean } \pm \text { sd }\end{array}$ \\
\hline 11 years & 29 & $5.86 \pm 0.62$ & 30 & $5.862 \pm 0.48$ & 29 & $16.51 \pm 1.90 \%$ & 30 & $17.22 \pm 2.35 \%$ \\
\hline 12 years & 57 & $6.59 \pm 1.06$ & 44 & $6.40 \pm 1.01$ & 57 & $16.30 \pm 2.33 \%$ & 44 & $16.07 \pm 1.99 \%$ \\
\hline 13 years & 82 & $7.27 \pm 0.86$ & 71 & $6.88 \pm 0.95$ & 82 & $15.31 \pm 2.07 \%$ & 71 & $16.16 \pm 2.15 \%$ \\
\hline 14 years & 81 & $6.90 \pm 0.98$ & 106 & $6.88 \pm 0.87$ & 81 & $14.82 \pm 2.12 \%$ & 106 & $16.40 \pm 2.21 \%$ \\
\hline & 249 & $6.83 \pm 1.02$ & 251 & $6.67 \pm 0.95$ & 249 & $15.52 \pm 2.22 \%$ & 251 & $16.37 \pm 2.19 \%$ \\
\hline
\end{tabular}

Table-4: Relative weight of backpack and sign, symptoms

\begin{tabular}{|c|c|c|c|c|c|c|c|c|c|c|c|c|}
\hline \multirow{2}{*}{$\begin{array}{c}\text { Relative } \\
\text { Wt. of } \\
\text { Bag }\end{array}$} & \multicolumn{4}{|c|}{ Male } & \multicolumn{4}{|c|}{ Female } & \multicolumn{4}{|c|}{ Total } \\
\hline & $\mathbf{N}$ & Sym & $\begin{array}{c}\text { sig } \\
\text { n }\end{array}$ & P value & n & Sym & sign & $P$ value & n & Sym & sign & $P$ value \\
\hline$\leq 11 \%$ & 13 & 1 & 0 & $1.000(\mathrm{NS})$ & 1 & 0 & 0 & NA & 14 & 1 & 0 & $1.000(\mathrm{NS})$ \\
\hline $12 \%$ & 21 & 2 & 0 & $0.472(\mathrm{NS})$ & 8 & 0 & 0 & NA & 29 & 2 & 0 & $0.472(\mathrm{NS})$ \\
\hline $13 \%$ & 18 & 5 & 0 & $0.054(\mathrm{NS})$ & 16 & 0 & 0 & NA & 34 & 5 & 0 & $0.063(\mathrm{NS})$ \\
\hline $14 \%$ & 45 & 12 & 0 & $0.000 * * *$ & 35 & 5 & 0 & $0.063(\mathrm{NS})$ & 80 & 17 & 0 & $0.000 * * *$ \\
\hline $15 \%$ & 49 & 24 & 0 & $0.000^{* * *}$ & 49 & 32 & 0 & $0.000 * * *$ & 98 & 56 & 0 & $0.000 * * *$ \\
\hline$\geq 16 \%$ & 103 & 93 & 15 & $0.000 * * *$ & 142 & 130 & 28 & $0.000 * * *$ & 254 & 223 & 43 & $0.000^{* * *}$ \\
\hline
\end{tabular}

Note: $n=$ number, Sym= Symptoms, NA= Not applicable (Chi-square test cannot be applied), NS = Not significant statistically. $* * *=$ Statistically highly significant

Table-5: Details of Musculoskeletal symptoms and signs

\begin{tabular}{|c|c|c|c|c|c|c|}
\hline & \multicolumn{3}{|c|}{ Musculoskeletal Symptoms } & \multicolumn{3}{|c|}{ Musculoskeletal Signs } \\
\hline $\begin{array}{l}\text { Total Children } \\
\quad(n=500)\end{array}$ & Neck pain & Back pain & Shoulder pain & $\begin{array}{c}\text { Redness } \\
\text { below Straps }\end{array}$ & Tenderness & $\begin{array}{c}\text { Limitation of } \\
\text { Movements }\end{array}$ \\
\hline $\begin{array}{c}\text { Symptomatic } \\
\text { children } 304 \\
(60.6 \%)\end{array}$ & $73(24 \%)$ & $255 \quad(83.88 \%)$ & $247(81.25 \%)$ & $25(8.2 \%)$ & $42(13.8 \%)$ & $6(1.97 \%)$ \\
\hline
\end{tabular}




\section{Discussion}

Carrying the luggage over the back has been practiced since long back. Initially mostly seen with soldiers, trackers and hunters; now commonly seen in most others. It is very common site all over the world to see schoolchildren using the backpacks to carry their educational material, lunchboxes, water bottles and other accessory material. It has become a common site in Indian Urban and Rural children also.

Pediatric spine is in critical stage of development in adolescent age group. Linear growth acceleration begins in early adolescence for both genders, with $15-20 \%$ of adult height accrued during puberty. Males and females have different pace, peaks and periods of growth. Their skeletal growth precedes muscle growth and bone growth precedes bone mineralization. Since different components of axial skeleton are growing differentially in adolescent period, they are at increased risk of fractures, sprains and strains. [1,13]. Musculoskeletal symptoms in children related to back can be multi factorial in origin. Use of heavy backpacks and improper carrying of backpacks remain one of the important causes after ruling out obvious causes like trauma, congenital musculoskeletal problems, poor physical built up, lack of exercise, excessive use of computers and intense physical activity. Use of backpack on posterior aspect of body shifts center of gravity. It leads to postural compensation of spine by bending forward. These alterations may cause back pain and injury by stressing the ligaments or muscles in the back or by changing the forces applied to intervertebral discs. [14] Depending upon effect of variables like physical characteristics of backpack, relative weight of backpack, method of carrying it, duration of carrying it, co-existing musculoskeletal problems; child is prone to get musculoskeletal problems. Adverse effects of backpack use like back pain, postural changes, decreased lung capacity have been described in various studies. [3-9,14,15,18,21,24,27,28] Narrow straps dig painfully into shoulders and can hinder circulation, causing numbness or tingling in the arms, which over time may cause weakness in the hands. Slinging a backpack over one shoulder causes a person to lean to one side to compensate for the uneven weight, curving the spine. Over time, this can cause lower and upper back pain, strained shoulders and neck, and even functional scoliosis, or curvature of the spine. After controlling variables like physical characteristics of backpack and carrying method, weight of backpack appears to be important cause for musculoskeletal adverse effects. Heavy school bags result in several postural changes at the head and trunk placing soft tissues at a biomechanical disadvantage resulting in fatigue and injury. This can result in repetitive stress injuries to the growing spine.

Most recommendations consider relative weight of backpack in the range of $10-15 \%$ as safe. [13,30]. In our study, mean absolute weight of the backpack was found to be $6.75 \pm 0.99 \mathrm{~kg}$ and relative weight of backpack $15.95 \pm 2.24 \%$. Relative weight of backpack was higher in female children $(16.37 \pm 2.19 \%)$ than that seen in male children $(15.52 \pm 2.22 \%)$. Other Indian studies have similar findings $[3,5,14,15,16]$. $60.6 \%$ of participants had musculoskeletal adverse effects related to backpack use. $55.02 \%$ male and $66.53 \%$ female children suffered these side effects. This is consistent with findings of others. Sheir-Neiss GI et al found $74.4 \%$ children had back pain, Aundhakar $\mathrm{CD}$ et al found it in $57.1 \%$, Whittfield $\mathrm{J}$ found it in $77.1 \%$ students Pavithra Rajan in $55 \%$ children, Rageswarihariharan $\mathrm{A}$ in $62.3 \%$, Aminu A et al in 82.2\% [15,20,25,26,29]

All the participants carrying relative backpack weight of $11 \%$ or less did not show any musculoskeletal adverse effects. As relative weight of backpack increased to 12 and $13 \%$, participants started showing musculoskeletal symptoms however they were not statistically significant. When relative weight of backpack was $14 \%$ and more, musculoskeletal adverse effects became more frequent with increasing weight which was statistically highly significant. (Table 4). Physical signs were noted in participants carrying backpacks with relative weight of more than $16 \%$. Incidence of physical signs was more in females $(11.55 \%)$ as compared with males $(6.02 \%)$. Similar observation was noted in other studies also. $[14,15,16,26]$. Out of all 304 symptomatic children, musculoskeletal symptoms in the form of neck pain, back pain and shoulder pain were found in $73(24 \%)$, $255(83.88 \%)$ and $247(81.25 \%)$ children respectively. Musculoskeletal signs like redness below the strips, tenderness and limitation of movement were seen in 25 (8.2\%), $42(13.8 \%)$ and $6(1.97 \%)$ children respectively. Similar findings were noted in other studies. Deepak Sharan et al found upper back pain in $40 \%$, neck pain in $27 \%$, and shoulder pain in $20 \%$. [4]. Neama Mohamed El Magrabi et al (2015) in their study in Assiut city found prevalence of low back pain (68.9\%), shoulder or arm pain (66.7\%). [17] Whittfield J found. Symptoms 
were most prevalent in the neck, shoulders, upper back and lower back. [20] Erisa $\mathrm{S}$ et al found about $88.2 \%$ of pupils reported having body pain especially in the neck, shoulders and upper back. [22]. Rageswarihariharan, A et al found $68.3 \%$ had shoulder pain and $31.8 \%$ had back pain. [29]. Aminu A et al found neck pain in $48.6 \%$, backpain in $67.2 \%$, shoulder pain in $61.2 \%$. [26].

We found Relative weight of backpack $\leq 11 \%$ is safe to carry. In other studies, Mooer MJ et al found use of a $10 \%$ of body weight cutoff for safe use of backpacks for all grade levels. [19]. When relative weight of backpack exceeds $14 \%$, prevalence of musculoskeletal adverse effects significantly increased. Back pain and shoulder pain were predominant sites of discomfort. Hence relative weight of backpack $14 \%$ should be taken as cutoff to call it unsafe in this region with target to reduce it to $\leq 11 \%$.

\section{Conclusions}

In our study $60.6 \%$ of children in the age group of 11 14 years had some or the other musculoskeletal problems related to use of backpacks. It was more in females $(66.53 \%)$ as compared to males $(55.02 \%)$. Prevalence increased with increasing relative weight of backpack both in males and females. With relative weight of $\leq 11 \%$ most children were asymptomatic. Relative weight of $12 \%$ to $13 \%$ showed statistically insignificant prevalence of musculoskeletal symptoms. With relative weight of backpack $\geq 14 \%$ in males and $\geq$ $15 \%$ in females prevalence increased which was statistically significant. A steep rise was seen in musculoskeletal symptoms from $57 \%$ to $91 \%$ in children with relative weight of $15 \%$ and $\geq 16 \%$ respectively. Trend of prevalence of musculoskeletal symptoms was similar in males as well as females. Relative weight of backpack $\leq 11 \%$ is safe to carry. As relative weight of backpack increases to $\geq 15 \%$, majority of adolescent children in this region are at risk of developing musculoskeletal adverse effects.

Limitations: This study has few limitations. Sample size is small. Hence findings of this study may not be generalized. It needs more studies from this region to confirm the findings. Similarly duration of carrying backpack was not taken into account due to feasibility problem.

Acknowledgement: We sincerely thank the children, parents and staff of all schools for their co-operation in this study.
Funding: Nil, Conflict of interest: Nil

Permission from IRB: Yes

\section{References}

1.Cynthia Holland-Hall and Gale R. Burstein. Adolescent Physical and Social Development. In: Nelson Textbook of Pediatrics. First South Asia Edition. Elsevier;2016.p.926-931.

2.R. Justin Mistovich and David A. Spiegel. Back Pain in Children. In: Nelson textbook of Pediatrics. First South Asia Edition. Elsevier;2016.p.3292-3293.

3. Shyamal Koley and Navneet Kaur. An Association of Backpack Weight and Postural Habits in School Going Children of Amritsar, Punjab, India. Anthropologist (2010); 12(2): 107-111.

4.Deepak Sharan, Ajeesh P S, Jerrish A Jose, Sukrit Debnath and Manjula M. Backpack injuries in Indian School children : risk factors and clinical presentations. Work 41(2012):929-932.

5.Janakiraman Balamurugan. School Bags and Musculoskeletal Pain Among Elementary School Children In Chennai City. International journal of medical science and clinical Invention. 2014; Volume 1 issue 6: 302-309.

6.Rai A, Agarwal S, Bharti S. Postural Effect of Back Packs on School Children: Its Consequences on Their Body Posture. IJHSR. 2013; 3(10): 109-116.

7.Rateau, Margaret R. Use of Backpacks in Children and Adolescents: A Potential Contributor of Back Pain. Orthopaedic Nursing: March/April 2004; Volume 23 Issue 2: 101-105.

8.Skaggs DL, Early SD, D'Ambra P, Tolo VT, Kay RM. Back pain and backpacks in school children. J Pediatr Orthop. 2006 May-Jun;26(3):358-63.

9.Walicka-Cupryś K, Skalska-Izdebska R, Rachwał M, Truszczyńska A. Influence of the Weight of a School Backpack on Spinal Curvature in the Sagittal Plane of Seven-Year-Old Children. Biomed Res Int. 2015;2015:817913.

10.Zeinab Javadivala, Hamid Allahverdipour, Iman Dianat, and Mohsen Bazargan Awareness of Parents about Characteristics of a Healthy School Backpack. Health Promot Perspect. 2012; 2(2): 166-172.

11.G N Lucas. Backpacks in children. Editorial. Sri Lanka Journal of Child Health, 2011; Volume 40, Issue $1: 1-3$. 
12.Karl E. Back Pain. In: RathenTachdjian's Pediatric Orthopaedics. $5^{\text {th }}$ ed. Elsevier; Volume 2 .p.90-100.

13.Ujjwal K Debnath. Current Concepts in the Management Of Early- onset Idiopathic Scoliosis. Pediatr Health. 2010; 4(3):343-354.

14.Mayank, Mohan, Upender Singh, and Nishat Quddus. Effect of backpack loading on cervical and shoulder posture in Indian school children. Indian Journal of Physiotherapy and Occupational Therapy-An International Journal1.2 (2007): 3-12.

15.Aundhakar CD, Bahatkar KU, Padiyar MS, Jeswani DH, Colaco S. Back pain in children associated with backpacks. Indian J Pain 2015;29:29-31.

16. Pascoe DD, Pascoe DE, Wang YT, Shim DM, Kim $\mathrm{CK}$. Influence of carrying book bags on gait cycle and posture of youths. Ergonomics 1997;40:631-41.

17.Neama Mohamed El Magrabi, Safaa Rashad Mahmoud, and Yousrria El-Sayed Yousef. Awareness of parents about school backpack and its related musculoskeletal disorders in Assiut City. IOSR Journal of Nursing and Health Science (IOSR-JNHS) e-ISSN: 2320-1959.p- ISSN: 2320-1940 Volume 4, Issue 6 Ver. V (Nov. - Dec. 2015), PP 05-11.

18.Ramprasad M, Alias J, Raghuveer AK. Effect of Backpack Weight on Postural Angles in Preadolescent Children. Indian Pediatr. 2010 (Jul 7); 47 (7): 575-580.

19. Moore MJ, White GL, Moore DL.Association of Relative Backpack Weight With Reported Pain, Pain Sites, Medical Utilization, and Lost School Time in Children and Adolescents. J Sch Health. 2007 (May); 77 (5): 232-239

20.Whittfield J, Legg SJ, Hedderley DI. Schoolbag Weight and Musculoskeletal Symptoms in New Zealand Secondary Schools. Applied Ergonomics 2005 (Mar); 36 (2): 193-198

21.Kistner F, Fiebert I, Roach K. Effect of Backpack Load Carriage on Cervical Posture in Primary Schoolchildren. Work.2012(Jan1);41(1):99-108.
22.Erisa S Mwaka, Ian G Munabi, William Buwembo, John Kukkiriza and Joseph Ochieng. Musculoskeletal pain and school bag use: a cross-sectional study among Ugandan pupils. BMC Research Notes 2014, 7:222

23.Sheir-Neiss GI, Kruse RW, Rahman T, Jacobson LP, Pelli JA. The association of backpack use and back pain in adolescents. Spine (Phila $\mathrm{Pa}$ 1976). 2003 May 1;28(9):922-30.

24.Jagdish Hundekari, Kalyan Chilwant, Shashank Vedpathak, Satish Wadde. Does alteration in backpack load affects posture of schoolchildren? I OSR Journal of Dental and Medical Sciences. Volume 7, Issue 4 (May.- Jun. 2013), PP 71-75.

25.Pavithra Rajan and Anand Koti. Ergonomic Assessment and Musculoskeletal Health of the Underprivileged School Children in Pune, India. Health Promot Perspect. 2013; 3(1): 36-44.

26.Aminu A. Ibrahim, Ayyappan Jayavel, Surajo Kamilu Suleiman, Jibril M. Nuhu. Influence of Schoolbag Use on Musculoskeletal Discomforts among University Students. International Journal of Health Sciences \& Research. Vol.5; Issue:5;May2015:222-231.

27.Deepali Nivrutti Hande, Neesha Shinde, S.M.Khatri, Pallavi Dangat. The Effect of Backpack on Cervical and Shoulder Posture in Male Students of Loni. International Journal of Health Sciences \& Research. Vol.2; Issue: 3; June 2012: 72-79.

28.Lai JP, Jones AY: The effect of shoulder-girdle loading by a school bag on lung volumes in Chinese primary school children. Early Hum Dev2001,62:79-86.

29.Rageswarihariharan A. Zechariah Jebakumar, K Madhumathi. Backpack- Bad Pack an Iisue, Backpack Uusage and its Implications on Indian School Children, an Observational Study on the Impact of Backpack Betwween Rural and Urban School Children. Physiotherapy and Occupational Therapy Journal, Volume 2009; 2(1): 5-11.

30. Brackley, Heather M, Stevenson, Joan M. Are children's backpack weight limits enough? Spine 2004; 29(19): 2184-90.

\section{How to cite this article?}

Mohan A. Patil, Sumana S, Shagale N. Musculoskeletal effects of heavy backpacks in school children of 11-14 years of age. Int J Pediatr Res.2016;3(6):421-426.doi:10.17511/ijpr.2016.i06.09. 